Article

\title{
Dry Sliding Wear Performance of ZA27/SiC/GraphiteComposites
}

\author{
Nenad Miloradović *, Rodoljub Vujanac, Slobodan Mitrović ${ }^{(D)}$ and Danijela Miloradović \\ Faculty of Engineering, University of Kragujevac, Sestre Janjić 6, 34000 Kragujevac, Serbia \\ * Correspondence: mnenad@kg.ac.rs; Tel.: +381-34-335990
}

Received: 25 May 2019; Accepted: 24 June 2019; Published: 26 June 2019

\begin{abstract}
The paper describes the wear performance of zinc-aluminium ZA27 alloy, reinforced with silicon-carbide $(\mathrm{SiC})$ and graphite $(\mathrm{Gr})$ particles. The compo-casting technique produced the composite samples. The tested samples were: ZA27 alloy, ZA27/5\%SiC composite, and ZA27/5\%SiC/3\%Gr hybrid composite. A block-on-disc tribometer was used during wear tests under the dry sliding conditions by varying the normal loads and sliding speeds. The sliding distance was constant during tests. The microstructure of the worn surfaces of the tested materials was analysed using the scanning electronic microscope (SEM) and the energy dispersive spectrometry (EDS).
\end{abstract}

Keywords: hybrid composite; wear performance; ZA27 alloy

\section{Introduction}

Zinc-aluminium alloys are used for various industrial applications. They have favourable properties, such as: A low melting point, high tensile strength and hardness, easy machinability, high castability, good corrosion resistance, and low manufacturing costs.

The effects of different reinforcement materials, like $\mathrm{SiC}$, graphite, $\mathrm{Al}_{2} \mathrm{O}_{3}$ and $\mathrm{ZrO}_{2}$ on tribological behaviour of composites based on ZA27 alloy have been the research topic of many authors. Their research results clearly show that reinforcement particles improve the tribological behaviour of the base $\mathrm{Zn}-\mathrm{Al}$ alloy.

To improve the wear performance of zinc-based alloys, $\mathrm{SiC}$ is added as reinforcement to form composites. Thus, the dimensional stability and wear resistance of the composites were improved [1,2]. The sliding wear tests were conducted using a pin-on-disc method. The composite melt was prepared with $10 \mathrm{wt} . \% \mathrm{SiC}$ particles of $50 \mu \mathrm{m}-100 \mu \mathrm{m}$ size. The author concludes that the wear-rate of the zinc-based alloy and its composite containing $\mathrm{SiC}$ particles increases with load in dry and lubricated conditions.

Effect of the $\mathrm{SiC}$ particles reinforcement on the dry sliding wear behaviour of ZA27 alloy composites was investigated in Reference [3]. The sliding wear tests were conducted at loads of $3 \mathrm{~kg}, 4 \mathrm{~kg}, 5 \mathrm{~kg}$ and $6 \mathrm{~kg}(29.4 \mathrm{~N}, 39.2 \mathrm{~N}, 49.1 \mathrm{~N}$ and $58.9 \mathrm{~N}$, respectively) and rotational speeds of $200 \mathrm{rpm}, 250 \mathrm{rpm}$ and $300 \mathrm{rpm}$. It has been noticed that the observed composites exhibit abrasion wear at low loads and dominant delamination wear at high loads.

Authors of several papers have investigated and reported a positive tribological effect of graphite particles on ZA27 alloys in the dry sliding tests [4-6]. In Reference [4], the graphite particulate size was $50 \mu \mathrm{m}-100 \mu \mathrm{m}$ and its contents in the composites were $0 \%, 1 \%, 3 \%$ and $5 \%$. It was found that the increase in graphite content within the ZA27 matrix resulted in a significant increase of ductility and strength, but a decrease of hardness. In Reference [5], ZA27 based composites were prepared with $0 \%$, $4 \%, 6 \%$ and $8 \%$ of graphite particulate addition using the compo casting method. Experimental results show that the damping capacity increases with addition of graphite. 
Unlike more conventional materials such as cast iron [7], this effect was obtained with the tribo-induced graphite film on the contact surface of the composite. The composite material based on ZA27 alloy with $2 \mathrm{wt} . \%$ of graphite particles was tested under dry and lubricated sliding conditions [8]. The authors have shown that the difference between the wear resistance of composite and the matrix alloy increases with the increase of the applied load and the sliding speed. This was attributed to solid lubrication provided by the formation of the graphite-rich film on the tribo-surface.

The metal-matrix composites (MMCs) have better mechanical properties, such as: Higher tensile strength, temperature stability and elastic modulus compared to unreinforced alloys $[9,10]$. The results from Reference [9] show that ZA alloys wear-rate strongly depends on the applied load. This dependence was found to be nonlinear. In addition, the transfer of Fe from the disc to the sample was noticed in dry sliding conditions. The research confirmed that the wear properties of the matrix alloys improve with the addition of $\mathrm{SiC}$ particles. Based on the experimental results from Reference [10], the authors have modelled dry sliding wear behaviour using a statistical approach method. They observed the effect of interactions between the sliding speed, the applied load and the sliding distance on wear behaviour of metal matrix composites. The increase of the sliding speed during tests generated the decrease of the wear volume loss. The increase in applied load and sliding distance caused an increase in the wear volume loss. The developed model proved to be an effective tool for evaluation of composites dry sliding wear performance.

The Taguchi design of the experiments as means for optimisation of the wear test parameters was used to describe the tribological behaviour of $\mathrm{ZA} 27 / 10 \% \mathrm{SiC}$ composites and $\mathrm{ZA} 27 / 10 \% \mathrm{SiC} / 3 \% \mathrm{Gr}$ hybrid composites in Reference [11]. It has been found that the contact load has the greatest influence on the wear-rate $(85.85 \%)$, while the sliding speed $(7.09 \%)$ and graphite content $(5.24 \%)$ have a smaller influence. The interactions between main parameters (graphite, load, sliding speed) have significantly less influence than the parameters themselves.

The papers [12,13] deal with the wear characteristics of ZA27/5\%SiC/3\%Gr and ZA27/10\%SiC/1\%Gr hybrid composites, respectively. Both composites were produced by using the compo-casting method and tested for different applied loads, sliding speeds and sliding distances in order to prove their better resistance to wear. Based on experimental tests conducted with the "block-on-disc" tribometer, variations in wear volume loss in dry sliding conditions were presented. By monitoring the wear process, the advantages of the tested hybrid composites as advanced tribo-materials was observed.

The hard reinforcements (such as $\mathrm{SiC}$ ) enhance the hardness and abrasive wear resistance of $\mathrm{Zn}$-Al alloy, but reduce its machinability and conductivity [14]. It has been concluded that graphite, as a solid lubricant with good conductivity, can be dispersed in $\mathrm{Zn}$-Al alloy together with $\mathrm{SiC}$. The increase in $\mathrm{SiC}$ content induces the increase of the ultimate tensile strength of the composite material.

Study in Reference [15] was focused on processing and physical and mechanical characterisation of the ZA-27 metal matrix composites reinforced with $\mathrm{SiC}$ particles, with different weight percentage ( 0 to $9 \mathrm{wt. \%}$ ). It was concluded that the observed composites have low porosity and improved micro-hardness and tensile strength compared to the pure ZA27 alloy. The authors conclude that the erosion characteristics of these composites can also be successfully analysed using Taguchi experimental design scheme.

In Reference [16], experiments were conducted on Al-Gr composites and Al-SiC-Gr hybrid composites using the pin-on-disc equipment. Investigations have shown that the optimally combined $\%$ reinforcement is around $7.5 \%$ for any value of the sliding distance, sliding speed, and load within the considered range. Application of aluminium based composite materials in automotive industry enables the production of the lighter, safer and more energy efficient vehicles.

Tribological tests of aluminium based composite materials were described in Reference [17]. A matrix alloy was reinforced with $10 \% \mathrm{Gr}$ and $3 \% \mathrm{SiC}$. It was shown that an increase in the $\mathrm{SiC}$ fraction causes an increase of the wear resistance of hybrid composites, while decreasing the wear.

Results from References [18-20] indicate that the alumina particle content can have a positive influence on the tribological behaviour of the ZA27 alloy-based hybrid composite. 
The tribological tests were conducted using the pin-on-disc wear test equipment under the dry sliding condition [18]. Wear process was studied using analysis of variance technique and regression equations. In Reference [19], the alumina percentage in the composites was varied from 0 to $9 \%$. The hybrid composite with $9 \% \mathrm{Al}_{2} \mathrm{O}_{3}$ and $3 \%$ graphite was found to have the highest wear resistance. The paper [20] investigated the composites with 3,5, and $10 \mathrm{wt} . \%$ of $\mathrm{Al}_{2} \mathrm{O}_{3}$ particles that were produced by the compo-casting procedure. The difference in the wear resistance between the composite and the matrix alloy was increased with the increase of $\mathrm{Al}_{2} \mathrm{O}_{3}$ particle content.

Composite, which is improved by reinforcements with alumina and graphite nano-particles, has preferable microstructure stability and tribological behaviour than conventional MMCs [21].

In References [22,23], the authors state that nano-particles can improve the base material, and contribute to wear resistance, damping properties, and mechanical strength. However, thus obtained nanocomposites are seldom used in commercial applications, because of their recent development. Due to their good thermal conductivity, wear resistance and high specific strength, they are suitable as materials for aircraft brakes, bicycle frames, heat sinks and solders, but also in aerospace and automotive industries for making the cylinder liners, aircraft fins, disk brakes and calipers.

Increase of mass or volumetric share of $\mathrm{SiC}, \mathrm{Al}_{2} \mathrm{O}_{3}$ and graphite changes the tribological characteristics of MMCs. By combining the appropriate share of reinforcement materials, the optimal values of tribological characteristics of materials are achieved [24,25].

Good characteristics of the zinc-aluminium alloys have inspired researchers to reinforce them with already mentioned reinforcement materials. In this way, much more enhanced mechanical and tribological properties may be obtained. Based on the available research, some authors have separately studied the effects of reinforcing ZA27 with SiC and Gr. However, the majority of the research was dedicated to improving tribological properties of the ZA27 alloy-based composites. Not many of them have been focused on hybrid composites with the same substrate. Thus, this paper aims to investigate the tribological behaviour of hybrid composites compared to the base alloy. Acquired knowledge may be used to improve the existing solutions and lead to new industrial and engineering applications.

Zinc aluminium alloy ZA27 was used as a base material for the production of composites in this research. The following composites were analysed: $\mathrm{ZA} 27 / 5 \% \mathrm{SiC} / 3 \% \mathrm{Gr}$ hybrid composite and $\mathrm{ZA} 27 / 5 \% \mathrm{SiC}$ composite. Other researchers have rarely tested composites with a given percentage of reinforcement particles, therefore, the test results presented in this paper contribute to a better understanding of their wear performance.

\section{Materials and Methods}

The tested composite materials were successfully prepared using the compo-casting procedure, which is economical and enables a good distribution of the reinforcements in the composite structure. Previous preparation of reinforcement particles is not necessary, so the production becomes simpler and cheaper.

In order to obtain the composite materials, equipment consisting of the process part (melting furnace, mixer and crucible) and the part for temperature measurement, control and regulation (thermocouple and instrumentation). A two- phase compo-casting procedure was used. First, the infiltration of the particles into the semi-solid melt of the basic alloy was obtained by mixing. The graphite particles of size $15 \mu \mathrm{m}$ were added, while the average size of the SIC particles was $26 \mu \mathrm{m}$. After the operating temperature of $465^{\circ} \mathrm{C}$ was reached, mixing of melt with the rotational speed of the active part of the mixer of $500 \mathrm{~min}^{-1}$, lasting $2.5 \mathrm{~min}$ has been conducted in order to facilitate the infiltration of particles and to prevent thickening of melt. The second phase included the hot pressing of the obtained composite casts. 


\subsection{Structure of the Tested Materials}

Table 1 shows the chemical composition of the ZA27 alloy used for obtaining the composite materials.

Table 1. The chemical composition of ZA27 alloy.

\begin{tabular}{lcccccccc}
\hline Element & $\mathbf{A l}$ & $\mathbf{C u}$ & $\mathbf{M g}$ & $\mathbf{F e}$ & $\mathrm{Sn}$ & $\mathbf{C d}$ & $\mathbf{P b}$ & $\mathbf{Z n}$ \\
\hline wt.\% & 26.3 & 2.54 & 0.018 & 0.062 & 0.002 & 0.005 & 0.004 & balance \\
\hline
\end{tabular}

The hardness of the tested samples was: ZA27-124 Hv, ZA27/5\%SiC composite-147 Hv, ZA27/5\%SiC/3\%Gr hybrid composite- $145 \mathrm{Hv}$.

The metallographic analysis is a very powerful research tool that enables the review of the grain structure and the size of the reinforcement particles. Thus, the microstructure of the tested materials was observed by computer-aided optical microscope Meiji Techno's MT8500 (Meiji Techno Co., Ltd., Saitama, Japan). The specimens were polished and etched according to standard metallographic practice.

Figure 1a presents the microstructure of ZA27 alloy. The visible uniformity of the structure caused favourable mechanical properties of the tested materials. It can be seen that the structure of the sample of ZA27 alloy is typically dendrite. The microstructure of the matrix alloy revealed primary $\alpha$ dendrites, eutectoid $\alpha+\eta$ and meta-stable $\varepsilon$ phase. Similar observations have been made in References $[1,8,9,14]$. The structure is found to be homogeneous, consisting of light-coloured cores rich with aluminium, with a grey coloured extracted eutecticum made of $\alpha$ - and $\eta$-phase rich with zinc.

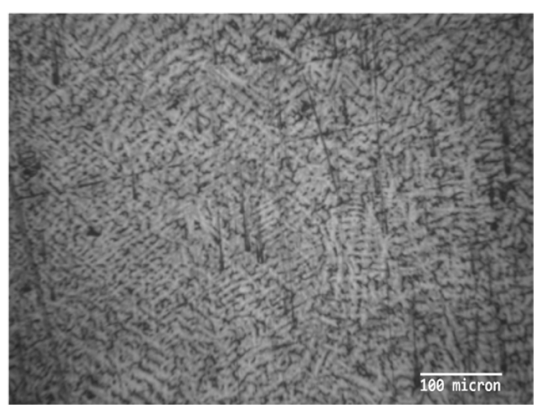

(a)

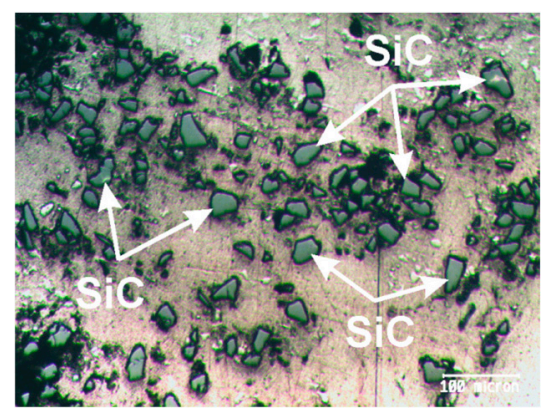

(b)

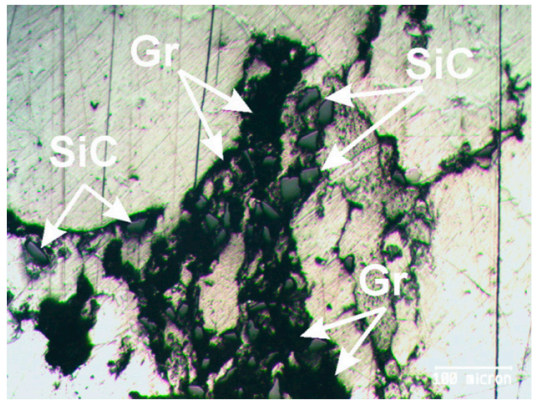

(c)

Figure 1. The microstructure of the tested materials: (a) ZA27 alloy; (b) ZA27/5\%SiC composite; (c) ZA27/5\% SiC/3\%Gr hybrid composite.

Microstructure of $\mathrm{ZA} 27 / 5 \% \mathrm{SiC}$ composite is given in Figure $1 \mathrm{~b}$ and microstructure of $\mathrm{ZA} 27 / 5 \% \mathrm{SiC} / 3 \% \mathrm{Gr}$ hybrid composites displayed in Figure 1c. The particles of $\mathrm{SiC}$ and $\mathrm{Gr}$ are indicated in the figures.

Reasonably homogeneous dispersion of the reinforcing particles is visible. The silicon carbide particles can be clearly identified when compared with graphite. The soft particles of graphite did not maintain their original size, because their erosion had occurred during the mixing procedure. 


\subsection{Testing Methods}

The measuring equipment consisted of five major component groups: Tribology testing device (tribometer), sensors, measuring amplifier, data acquisition system, and computer.

The tests of tribological characteristics of the ZA27 alloy and both composites were done using the block-on-disc tribometer with computer support. Tribometer configuration contains the power system (electric motor and drive), the system for setting the normal load and sliding speed, the system for self-aligning of the rotational disc and the stationary block, and the measuring system. The design of the special block carrier enables the transfer of the normal load in the direction of the disc axis. In this way, a contact along the whole length of the block on disk is obtained.

The dry sliding tests were conducted for sliding speeds of $0.25 \mathrm{~m} / \mathrm{s}, 0.5 \mathrm{~m} / \mathrm{s}$ and $1 \mathrm{~m} / \mathrm{s}$, normal loads of $10 \mathrm{~N}, 20 \mathrm{~N}$ and $30 \mathrm{~N}$ and sliding distance of $600 \mathrm{~m}$. The contact pairs were prepared according to the demands of ASTM G77-05 standard. All discs, made of 90MnCrV8 steel with a hardness of 62-64 HRC, had the diameter of $35 \mathrm{~mm}$ and surface roughness of $R_{\mathrm{a}}=0.3 \mu \mathrm{m}$. Dimensions of the blocks were $6.35 \mathrm{~mm} \times 15.75 \mathrm{~mm} \times 10.16 \mathrm{~mm}$. The blocks were made of the tested ZA27 alloy, $\mathrm{ZA} 27 / 5 \% \mathrm{SiC}$ composite and $\mathrm{ZA} 27 / 5 \% \mathrm{SiC} / 3 \% \mathrm{Gr}$ hybrid composite. The roughness of the contact surface of the test blocks was $R_{\mathrm{a}}=0.3 \mu \mathrm{m}$.

All the experiments were repeated five times per sample/condition. The wear track width at the block contact surface was selected as the basic parameter of wear. The measurement of the wear track width was conducted using the universal measuring microscope UIM-21 (GOMZ, Saint Petersburg, Russia). Its final values were calculated as the arithmetic mean of the five conducted measurements. Wear track width for different normal loads and sliding speeds were used for calculation of material wear-rate. Wear volume was calculated in accordance with ASTM G77-83 (based on the measured wear track width and the geometry of the contact pair, shown in References $[17,20])$ and used to calculate the wear-rate expressed in $\mathrm{mm}^{3} / \mathrm{m}$.

In order to understand the microstructure of the worn surfaces better, the SEM analysis of the tested alloy and MMCs was performed. The scanning electronic microscope JEOL JSM-6610LV (JEOL Ltd., Tokyo, Japan) was used. It has high resolution, and it is equipped with modern EDS module. Before the SEM analysis, the samples were cleaned thoroughly. The samples were immersed in ethanol, and then kept in an ultrasonic bath in order to achieve reliable results. The position of the samples in the sample chamber was tracked by a camera, which enabled a direct selection of position for signal recording.

\section{Results and Discussion}

The variations of the wear-rate in the dry sliding conditions are presented in corresponding diagrams for adopted sliding distance, sliding speeds and contact loads. Table 2 contains the measurement results of wear track width and calculated wear-rate for the three types of materials, and all combinations of sliding speeds and applied loads.

In order to observe the evolution of the wear process and to make comparisons, the results of the wear-rate for ZA27 alloy and composites were given in the same diagrams. In order to clearly state the difference between wear-rate levels, diagrams are given for one force level and one sliding speed level (Figures 2-4). Diagrams of the wear-rate obtained for the normal contact load of $10 \mathrm{~N}$ and three different sliding speeds are presented in Figure 2a-c.

Diagrams of wear-rate obtained for the normal contact load of $20 \mathrm{~N}$ and three different sliding speeds are presented in Figure 3a-c.

Diagrams of wear-rate obtained for normal contact load of $30 \mathrm{~N}$ and three different sliding speeds are presented in Figure $4 \mathrm{a}-\mathrm{c}$.

The research results are in accordance with similar research related to ZA27 based alloys and composites published in the literature $[2,3,11,13,20]$. It has been reported that the composite possesses better wear resistance than a matrix alloy under dry sliding conditions. The wear-rate of composites, as well as of the matrix alloy increased with the increase of applied load and sliding speed. 
Based on previous diagrams, it may be seen that the wear-rate curves have the same character both for ZA27 alloy and for the considered composites, but the composite materials exhibit smaller wear-rates compared to that of ZA27 alloy in all tests. In the initial phase of the tests, very intensive wear was observed, followed by a period of stabilisation. The intensive initial wear of the tested materials causes the larger slope of the curves at the beginning of the tests.

Table 2. Values of wear track width and wear-rate.

\begin{tabular}{|c|c|c|c|c|c|c|c|}
\hline \multicolumn{2}{|c|}{$\begin{array}{c}\text { Tested } \\
\text { Materials }\end{array}$} & \multicolumn{2}{|c|}{ ZA27 } & \multicolumn{2}{|c|}{$\mathrm{ZA} 27 / 5 \% \mathrm{SiC}$} & \multicolumn{2}{|c|}{$\mathrm{ZA} 27 / 5 \% \mathrm{SiC} / 3 \% \mathrm{Gr}$} \\
\hline$v / \mathrm{m} / \mathrm{s}$ & $\mathbf{F} / \mathbf{N}$ & $\begin{array}{l}\text { Wear Track } \\
\text { Width/mm }\end{array}$ & $\begin{array}{l}\text { Wear-Rate } / \mathrm{mm}^{3} / \mathrm{m} \times \\
10^{-3}\end{array}$ & $\begin{array}{l}\text { Wear Track } \\
\text { Width/mm }\end{array}$ & $\begin{array}{l}\text { Wear-Rate } / \mathrm{mm}^{3} / \mathrm{m} \times \\
10^{-3}\end{array}$ & $\begin{array}{l}\text { Wear Track } \\
\text { Width/mm }\end{array}$ & $\begin{array}{c}\text { Wear-Rate } / \mathrm{mm}^{3} / \mathrm{m} \times \\
10^{-3}\end{array}$ \\
\hline \multirow[b]{2}{*}{0.25} & 10 & 2.974 & 1.329 & 2.867 & 1.096 & 2.682 & 0.897 \\
\hline & 20 & 3.768 & 2.706 & 3.681 & 2.323 & 3.551 & 2.085 \\
\hline \multirow[t]{2}{*}{0.5} & 20 & 3.859 & 2.907 & 3.712 & 2.383 & 3.561 & 2.103 \\
\hline & 30 & 4.223 & 3.812 & 3.917 & 2.801 & 3.807 & 2.575 \\
\hline \multirow{2}{*}{1} & 10 & 3.424 & 2.029 & 3.111 & 1.401 & 2.814 & 1.037 \\
\hline & 20 & 3.985 & 3.202 & 3.795 & 2.547 & 3.564 & 2.108 \\
\hline
\end{tabular}

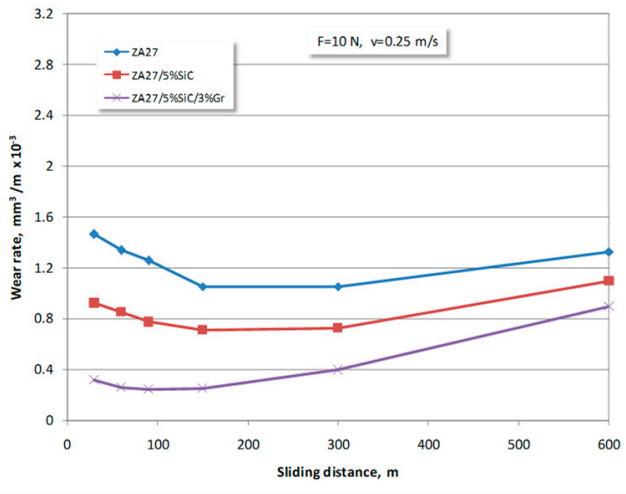

(a)

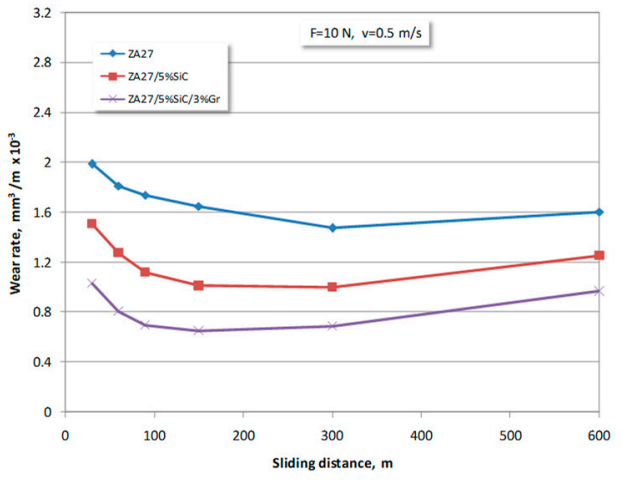

(b)

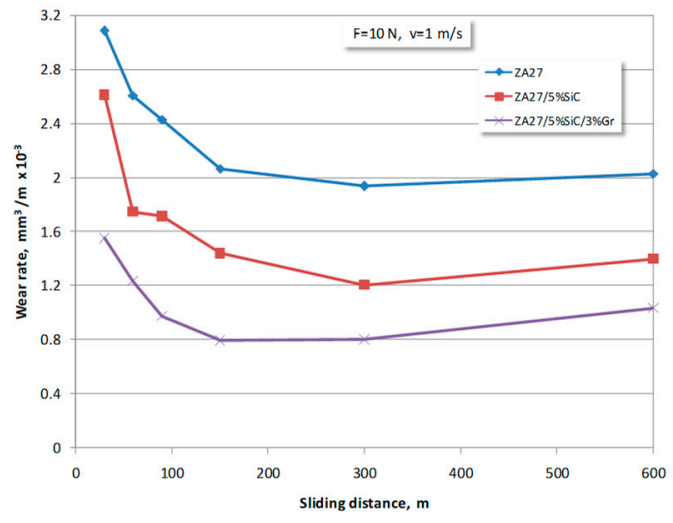

(c)

Figure 2. Wear-rate of the tested materials for normal load of $10 \mathrm{~N}$ and sliding speed of: (a) $v=0.25 \mathrm{~m} / \mathrm{s}$; (b) $v=0.5 \mathrm{~m} / \mathrm{s} ;(\mathbf{c}) v=1 \mathrm{~m} / \mathrm{s}$. 


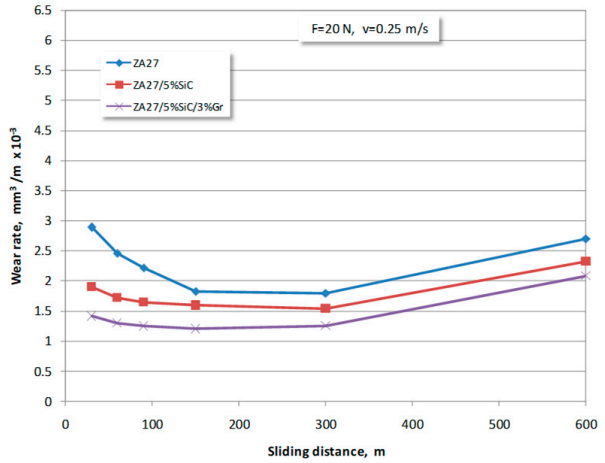

(a)

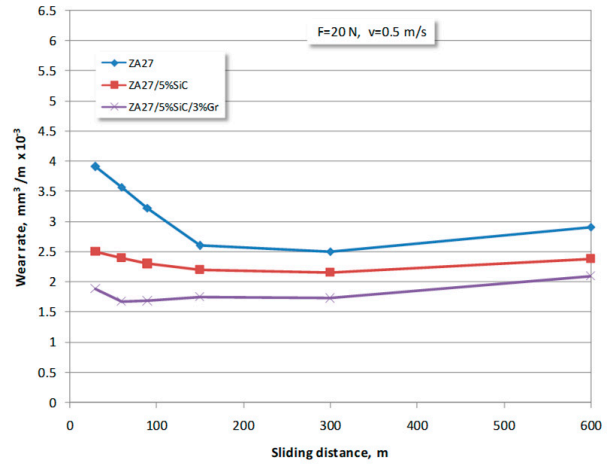

(b)

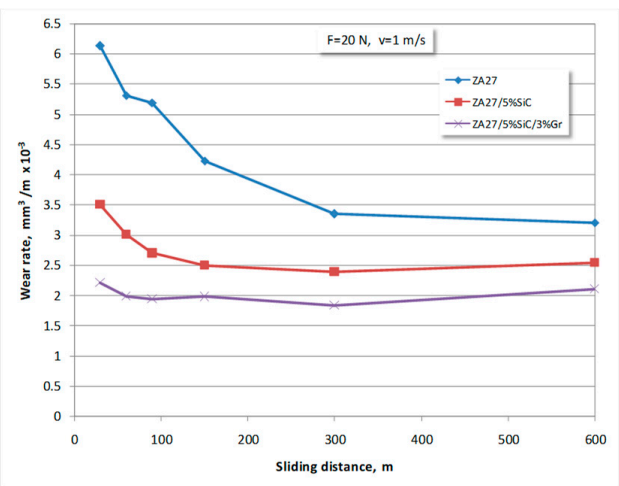

(c)

Figure 3. Wear-rate of the tested materials for normal load of $20 \mathrm{~N}$ and sliding speed of: (a) $v=0.25 \mathrm{~m} / \mathrm{s}$; (b) $v=0.5 \mathrm{~m} / \mathrm{s} ;(\mathbf{c}) v=1 \mathrm{~m} / \mathrm{s}$.

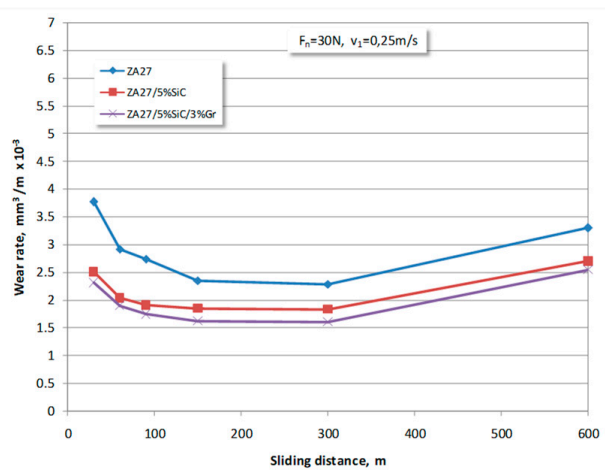

(a)

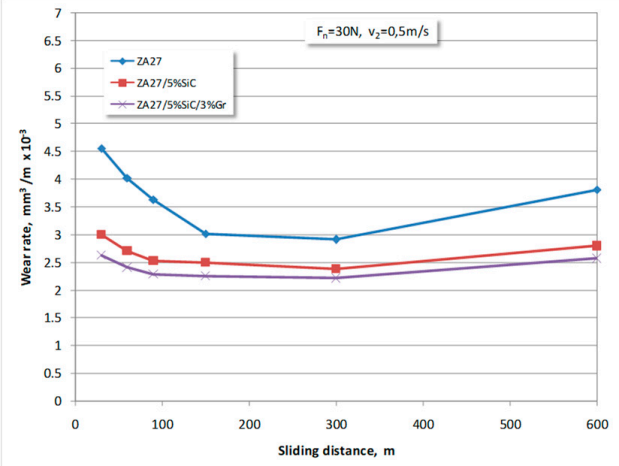

(b)

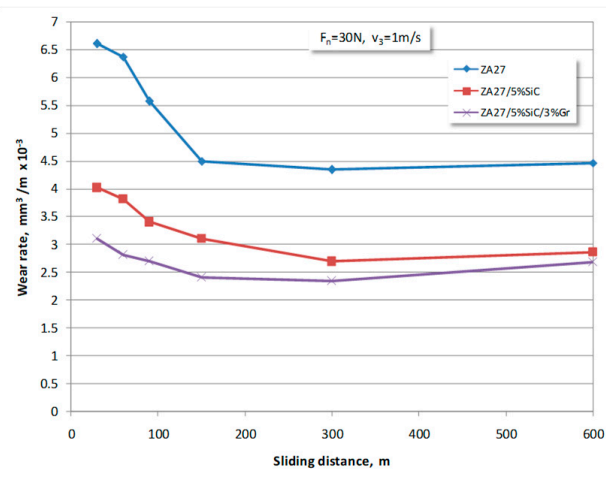

(c)

Figure 4. Wear-rate of the tested materials for normal load of $30 \mathrm{~N}$ and sliding speed of: (a) $v=0.25 \mathrm{~m} / \mathrm{s}$; (b) $v=0.5 \mathrm{~m} / \mathrm{s} ;$ (c) $v=1 \mathrm{~m} / \mathrm{s}$. 
Analytical and graphical dependences between the wear-rate and the adopted parameters are presented in Figure 5a-c. The power regression functions in the form given by Equation (1) were used:

$$
\text { wear rate }=C \cdot F_{n}{ }^{a} \cdot v^{b},
$$

where $C, a, b$ are constants, $F_{n}$ is the normal contact load, and $v$ is the sliding speed.

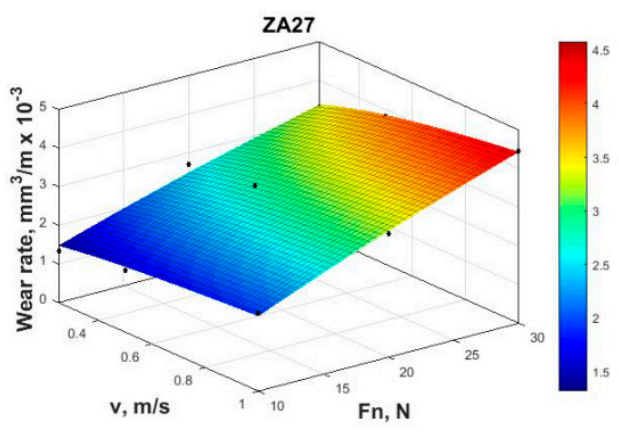

(a)

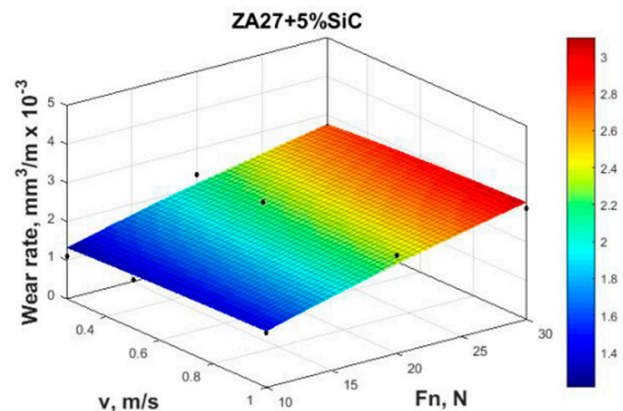

(b)

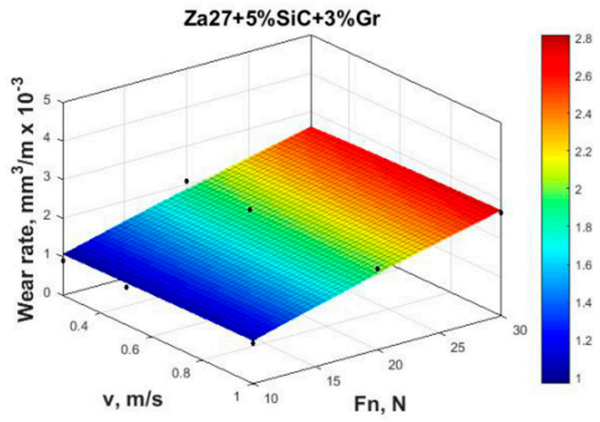

(c)

Figure 5. The wear-rate regression surface for: (a) ZA27 alloy (wear - rate $=0.3422 \cdot F_{n}{ }^{0.7533} \cdot v^{0.1979}$ ), $R^{2}=0.9878$, adj $R^{2}=0.9837 ;(\mathbf{b}) \mathrm{ZA} 27 / 5 \% \mathrm{SiC}$ composite (wear - rate $\left.=0.2403 \cdot F_{n}{ }^{0.7589} \cdot v^{0.0956}\right), R^{2}=$ 0.9379 , adj $R^{2}=0.9172 ;\left(\right.$ c) ZA27/5\%SiC/3\%Gr hybrid composite $\left(\right.$ wear - rate $\left.=0.1670 \cdot F_{n}{ }^{0.8222} \cdot v^{0.03125}\right)$, $R^{2}=0.9606$, adj $R^{2}=0.9475$.

By using the experimental results and curve fitting tool of the software package Matlab (R2015a, MathWorks, Inc., Natick, MA, USA), the regression coefficients were calculated with $95 \%$ confidence bounds. The goodness of fit was represented by $R^{2}$ and adjusted $R^{2}$ values. The very good correlation between the experimental data and empirical distributions was evident.

The obtained values of the wear-rates and their respective standard deviations for the ZA27 alloy and tested composites in the dry sliding conditions were given in comparative histograms in Figure 6 for the sliding distance of $600 \mathrm{~m}$. From the presented histograms, it can be clearly seen that the highest values of the wear-rate belong to the ZA27 alloy for all the testing regimes. Histograms also show that wear-rate increases by increasing the normal load and sliding speed. The largest value of the wear-rate corresponds to the highest sliding speed $(1 \mathrm{~m} / \mathrm{s})$ and the highest normal load $(30 \mathrm{~N})$. On the other hand, the lowest sliding speed $(0.25 \mathrm{~m} / \mathrm{s})$ and the lowest load $(10 \mathrm{~N})$ give the smallest wear values.

Figure 7a-c shows corresponding SEM micrographs for a normal load of $10 \mathrm{~N}$, sliding speed of $0.25 \mathrm{~m} / \mathrm{s}$ and sliding distance of $600 \mathrm{~m}$. A set of parallel grooves and scratches can be seen on the worn surface of all the tested materials. These grooves and scratches were made by sliding of the significantly harder rotation disc of the tribometer along the worn surfaces. In addition, these parallel and continuous scratches point to abrasive wear induced by the penetration of the hard $\mathrm{SiC}$ particles into a softer surface (mark A in Figure $7 \mathrm{~b}, \mathrm{c}$ ). 


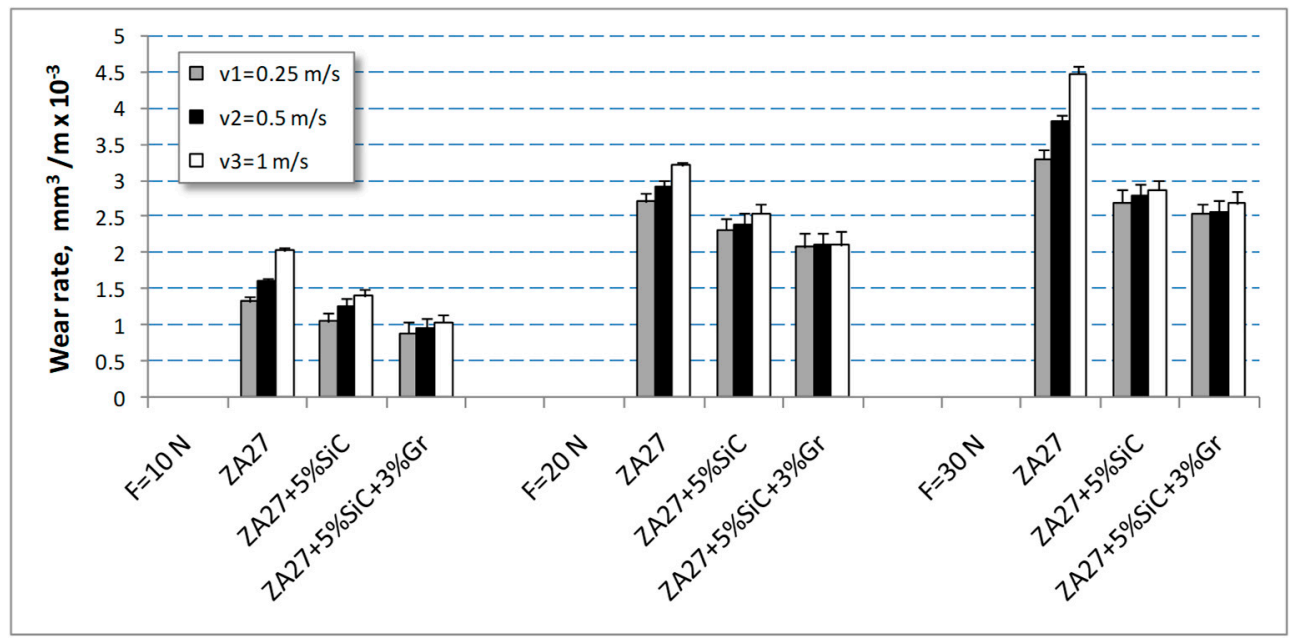

Figure 6. The wear-rate of the tested materials in the dry sliding conditions.

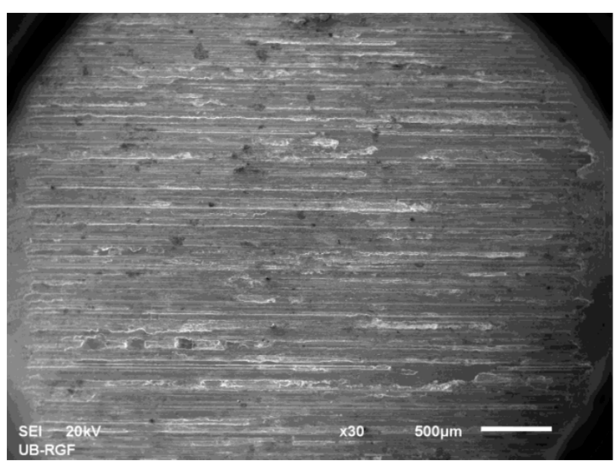

(a)

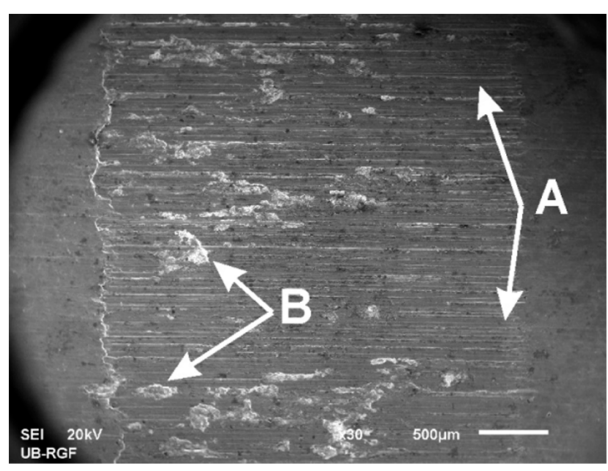

(b)

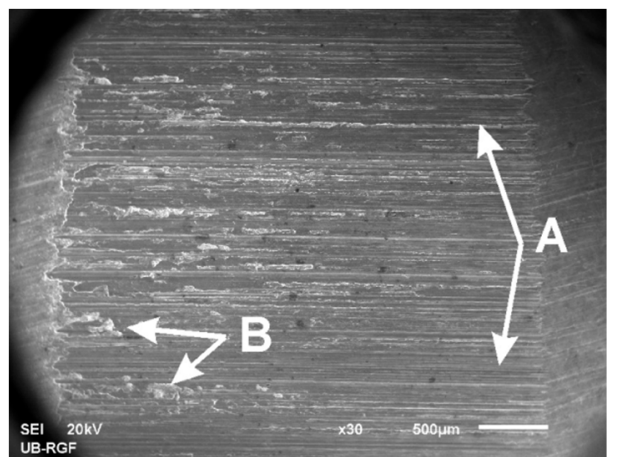

(c)

Figure 7. The appearance of the worn surfaces of the tested materials taken by SEM: (a) ZA27 alloy; (b) $\mathrm{ZA} 27 / 5 \% \mathrm{SiC}$ composite; (c) $\mathrm{ZA} 27 / 5 \% \mathrm{SiC} / 3 \%$ Gr hybrid composite.

Morphology of the worn surfaces and the obtained wear-rates point to the fact that the generation of the tribo-layers on the contact surface of the observed composites influences their overall wear behaviour.

The existence of the transfer of material between the contact surfaces has indicated that there was adhesive wear present. The adhesion wear occurs as a result of the creation and destruction of alternating friction connections. A part of worn material is ejected from the contact in the form of wear debris. The other part is stuck on the wear track. The pits irregular form and depth are also visible on the surface of the composite (mark B in Figure 7b,c).

Research from Reference [26] also states that wear tracks show typical abrasive wear for ZA27 alloy composite reinforced with $6 \%$ garnet at low loads. The authors point to the existence of the 
delamination process at higher loads. Removal of the surface layers by delamination was also detected in Reference [2].

In Reference [1], deep grooves were observed on the surfaces of the zinc-based matrix alloy, while they were not present on the smoother surface of the composite. Sticking of fine debris particles was observed in both cases. Similar observations have been made in References $[27,28]$. Rougher worn surface with deep grooves, damages and transfer material was attributed to intensive abrasive and adhesive wear.

The presence of the oxide layer formed on ZA27 was detected in Reference [29]. This layer protects the surface from deformation and damage by reducing the wear-rate.

The results obtained in this paper are in accordance with [30]. Deep grooves were observed on the worn surface of ZA27 alloy. Addition of graphite in hybrid composite makes the grooves shallower.

Figure 8 a shows the results of the chemical analysis of the micro-constituents of all tested materials obtained by the energy dispersive spectrometry.

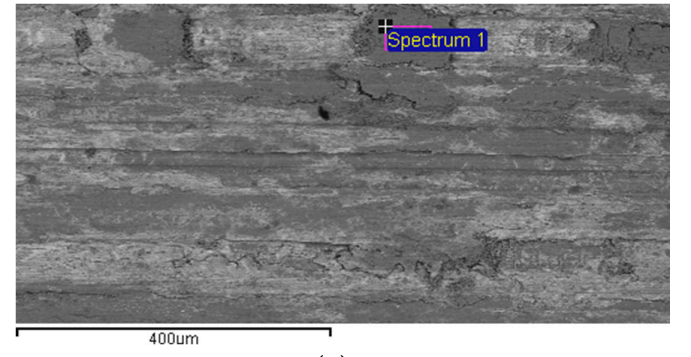

(a)

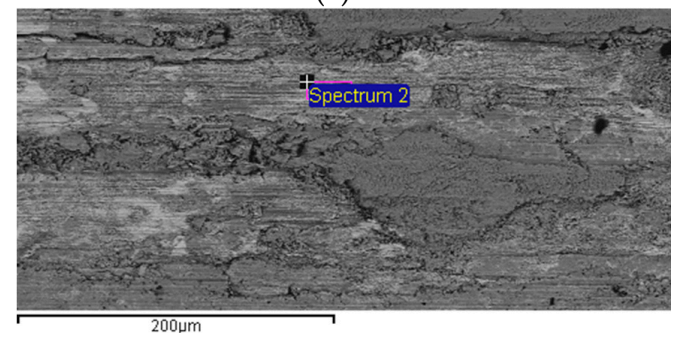

(c)

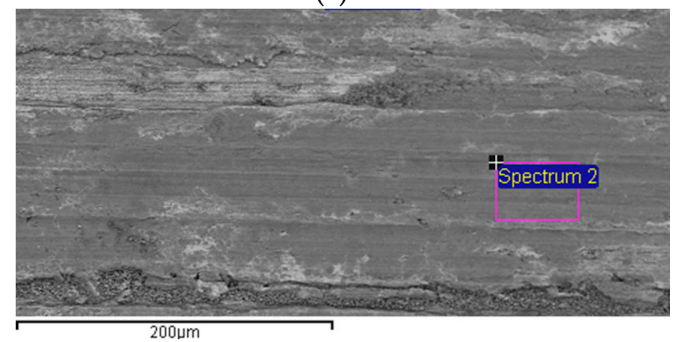

(e)

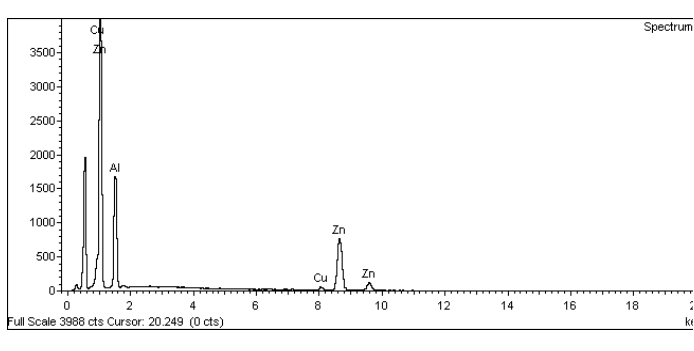

(b)

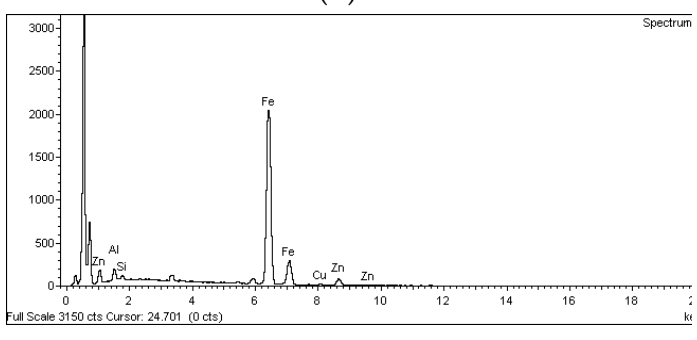

(d)

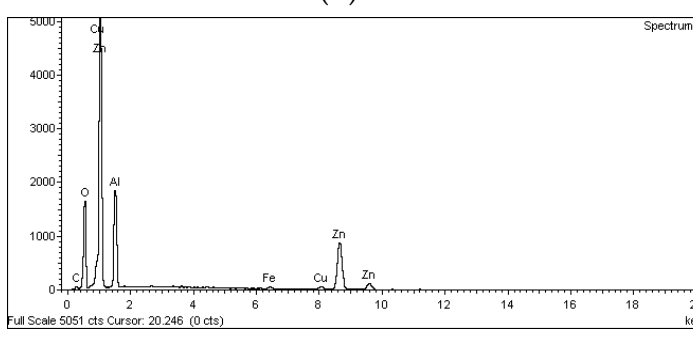

(f)

Figure 8. SEM micrographs and EDS analysis of the worn surfaces: (a) ZA27 alloy SEM micrograph; (b) ZA27 alloy EDS analysis; (c) ZA27/5\%SiC composite SEM micrograph; (d) ZA27/5\%SiC composite EDS analysis; (e) ZA27/5\%SiC/3\%Gr hybrid composite SEM micrograph; (f) ZA27/5\%SiC/3\%Gr hybrid composite EDS analysis.

Spectrum analysis confirms the presence of $\mathrm{Zn}, \mathrm{Al}, \mathrm{Si}, \mathrm{Gr}(\mathrm{C})$. The presence of $\mathrm{Fe}$ is detected due to material transfer from the rotational disc to the composite block (the same as in Reference [9]).

Generally, the wear performance of the tested materials is influenced by the formation of a mechanically mixed layer (MML) between the contact surfaces. Stability and thickness of the MML depend on the intensity of formation and destruction of the MML on the worn surface. The larger extent of material transfer is caused by severe wear conditions and higher frictional heating [20]. 
Creation of the MML is more prominent in alloys reinforced with ceramic particles. During the process of the dry sliding wear, hard ceramic particles scratch the counter surface materials. This phenomenon may explain the presence of Fe in the EDS spectrum analysis of the worn surface in Figure 8b. It can be concluded that tribo-layers contain $\mathrm{SiC}$ fractures, graphite, iron oxide and other particles contained by the observed hybrid composite, which was confirmed by EDS analysis.

The wear debris, fragmentation of oxide layer, transfer of materials between the contact surfaces and mixing of constituents contributes to the formation of the MML under an applied load. This stable layer prevents further direct contact between the contact surfaces. The decomposition of the unstable transfer layer may lead to restated contact and increase of wear.

\section{Conclusions}

Based on the existing theoretical knowledge and extensive experimental investigations, tribological knowledge of ZA27/SiC/Gr composites may be completed. Obtained excellent wear properties of the tested composite materials confirm that they can be used as advanced tribo-materials.

Based on the extensive experimental research presented in the paper, followed by corresponding analyses, the following conclusions can be made:

- The obtained experimental results indicate that reinforcement with the $\mathrm{SiC}$ particles and graphite can significantly improve tribological properties of the ZA27 alloy. The wear-rates of the tested composites are smaller than the wear-rate of theZA27 alloy for all applied sliding speeds and normal loads.

- The wear-rate behaviour has the same character for all the tested materials.

- Increase of the normal load causes the increase in wear-rate for the tested materials.

- The wear-rate also increases with the increase of the sliding speed.

- The microstructure analysis using an optical microscope and SEM shows that the particles are well dispersed in the ZA27 alloy matrix, as well as in the tested composites.

- The hybrid ZA27/SiC/Gr composites are tribologically superior to the ZA27/SiC composite in all the test conditions, due to lubrication obtained by the existence of the graphite film on the contact surface of the hybrid composite.

Author Contributions: Conceptualisation, N.M. and S.M.; methodology, N.M.; software, R.V. and D.M.; formal analysis, N.M., R.V. and D.M.; investigation, N.M.; resources, S.M.; writing-original draft preparation, N.M. and D.M.; writing—review and editing, N.M.; visualisation, N.M. and R.V.; supervision, S.M.

Funding: This research was funded by the Ministry of Education, Science and Technological Development of the Republic of Serbia, grant number TR35021.

Conflicts of Interest: The authors declare no conflict of interest.

\section{References}

1. Prasad, B.K. Investigation into sliding wear performance of zinc-based alloy reinforced with SiC particles in dry and lubricated conditions. Wear 2007, 262, 262-273. [CrossRef]

2. Prasad, B.K. Abrasive wear characteristics of a zinc-based alloy and zinc-alloy/SiC composite. Wear 2002, 252, 250-263. [CrossRef]

3. Sharma, S.C.; Girish, B.M.; Kramath, R.; Satish, B.M. Effect of SiC particle reinforcement on the unlubricated sliding wear behavior of ZA-27 alloy composites. Wear 1997, 213, 33-40. [CrossRef]

4. Seah, K.H.W.; Sharma, S.C.; Girish, B.M. Mechanical properties of cast ZA-27 graphite particulate composites. Mater. Des. 1996, 16, 271-275. [CrossRef]

5. Girish, B.M.; Prakash, K.R.; Satish, B.M.; Jain, P.K.; Prabhakar, P. An investigation into the effects of graphite particles on the damping behavior of ZA-27 alloy composite material. Mater. Des. 2011, 32, 1050-1056. [CrossRef]

6. Fragassa, C.; Minak, G.; Pavlovic, A. Tribological aspects of cast iron investigated via fracture toughness. Tribol. Ind. 2016, 38, 1-10. 
7. Fragassa, C.; Babic, M.; Minak, G. Predicting the tensile behaviour of cast alloys by a pattern recognition analysis on experimental data. Metals 2019, 9, 557. [CrossRef]

8. Babic, M.; Mitrovic, S.; Džunic, D.; Jeremic, B.; Bobic, I. Tribological Behavior of Composites Based on ZA-27 Alloy Reinforced with Graphite Particles. Tribol. Lett. 2010, 37, 401-410. [CrossRef]

9. Auras, R.; Schvezov, C. Wear Behaviour, Microstructure, and Dimensional Stability of As-Cast Zinc-Aluminium/SIC (Metal Matrix Composites) Alloys. Metall. Mater. Trans. A 2004, 35A, 1579-1590. [CrossRef]

10. Basavarajappa, S.; Chandramohan, G. Dry Sliding Wear Behaviour of Metal Matrix Composites: A Statistical Approach. J. Mater. Eng. Perform. 2006, 15, 656-660. [CrossRef]

11. Miloradović, N.; Stojanović, B.; Nikolić, R.; Gubeljak, N. Analysis of wear properties of Zn-based composites using the Taguchi method. Mater. Test. 2018, 60, 265-272. [CrossRef]

12. Mitrović, S.; Babić, M.; Miloradović, N.; Bobić, I.; Stojanović, B.; Dzunić, D.; Pantić, M. Wear Characteristics of Hybrid Composites Based on ZA27 Alloy Reinforced with Silicon Carbide and Graphite Particles. Tribol. Ind. 2014, 36, 204-210.

13. Miloradovic, N.; Stojanovic, B. Tribological behaviour of ZA27/10SiC/1Gr hybrid composite. J. Balkan Tribological Assoc. 2013, 19, 97-105.

14. Kiran, T.S.; Prasanna Kumar, M.; Basavarajappa, S.; Vishwanatha, B.M. Mechanical properties of as-cast ZA-27/Gr/SiCp hybrid composite for the application of journal bearing. J. Eng. Sci. Technol. 2013, 8, 557-565.

15. Mishra, S.K.; Biswas, S.; Satapathy, A. A study on processing, characterization and erosion wear behavior of silicon carbide particle filled ZA-27 metal matrix composites. Mater. Des. 2014, 55, 958-965. [CrossRef]

16. Suresha, S.; Sridhara, B.K. Effect of silicon carbide particulates on wear resistance of graphitic aluminium matrix composites. Mater. Des. 2010, 31, 4470-4477. [CrossRef]

17. Stojanović, B.; Babić, M.; Miloradović, N.; Mitrović, S. Tribological behaviour of A356/10SiC/3Gr hybrid composite in dry-sliding conditions. Mater. Technol. 2015, 49, 117-121.

18. Radhika, N.; Subramaniam, R. Wear behavior of aluminium/alumina/graphite hybrid metal matrix composites using Taguchi's techniques. Ind. Lubr. Tribol. 2013, 65, 166-174. [CrossRef]

19. Joshi, A.G.; Desai, R.S.; Prashanth, M.V.; Sandeep, S. Study on Tribological Behaviour of $Z A-27 / \mathrm{Al}_{2} \mathrm{O}_{3} / \mathrm{Gr}$ MMC. Int. J. Emerging Technol. 2016, 7, 117-122.

20. Babic, M.; Mitrovic, S.; Zivic, F.; Bobic, I. Wear Behavior of Composites Based on ZA-27 Alloy Reinforced by $\mathrm{Al}_{2} \mathrm{O}_{3}$ Particles Under Dry Sliding Condition. Tribol. Lett. 2010, 38, 337-346. [CrossRef]

21. Güler, O.; Çuvalci, H.; Gökdağ, M.; Çanakçi, A.; Çelebi, M. Tribological Behaviour of ZA27/ $/ \mathrm{Al}_{2} \mathrm{O}_{3} / \mathrm{Graphite}$ Hybrid Nanocomposites. Part. Sci. Technol. 2017, 36, 1-9. [CrossRef]

22. Casati, R.; Vedani, M. Metal Matrix Composites Reinforced by Nano-Particles-A Review. Metals 2014, 4, 65-83. [CrossRef]

23. Guaglianoni, W.C.; Cunha, M.A.; Bergmann, C.P.; Fragassa, C.; Pavlovic, A. Synthesis, Characterization and Application by HVOF of a WCCoCr/NiCr Nanocomposite as Protective Coating Against Erosive Wear. Tribol. Ind. 2018, 40, 477-487. [CrossRef]

24. Stojanovic, B.; Babic, M.; Mitrovic, S.; Vencl, A.; Miloradovic, N.; Pantic, M. Tribological characteristics of aluminium hybrid composites reinforced with silicon carbide and graphite. A review. J. Balkan Tribological Assoc. 2013, 19, 83-96.

25. Christopher, C.M.L.; Sasikumar, T.; Santulli, C.; Fragassa, C. Neural network prediction of aluminum-silicon carbide tensile strength from acoustic emission rise angle data. FME Trans. 2018, 46, 253-258. [CrossRef]

26. Ranganath, G.; Sharma, S.C.; Krishna, M. Dry sliding wear of garnet reinforced zinc/aluminium metal matrix composites. Wear 2001, 251, 1408-1413. [CrossRef]

27. Babic, M.; Mitrovic, S.; Jeremic, B. The influence of heat treatment on the sliding wear behavior of a ZA-27 alloy. Tribol. Int. 2010, 43, 16-21. [CrossRef]

28. Pola, A.; Montesano, L.; Gelfi, M.; La Vecchia, G.M. Comparison of the sliding wear of a novel Zn alloy with that of two commercial Zn alloys against bearing steel and leaded brass. Wear 2016, 368-369, 445-452. [CrossRef] 
29. Savaşkan, T.; Maleki, R.A.; Tan, H.O. Tribological properties of Zn-25Al-3Cu-1Si alloy. Tribol. Int. 2015, 81, 105-111. [CrossRef]

30. Kumar, N.S. Mechanical and Wear Behavior of ZA-27/SiC/Gr Hybrid Metal Matrix Composites. Mater. Today Proc. 2018, 5, 19969-19975. [CrossRef]

(C) 2019 by the authors. Licensee MDPI, Basel, Switzerland. This article is an open access article distributed under the terms and conditions of the Creative Commons Attribution (CC BY) license (http://creativecommons.org/licenses/by/4.0/). 